\section{In Reply: Micrometastases in Breast Cancer Sentinel Lymph Node}

\section{TO THE EDITORS:}

We thank Drs. Ziogas and Zografos for their comments regarding our recent publication in the Annals of Surgical Oncology. ${ }^{1}$

There are two fundamentally different questions regarding the presence of micrometastases in the sentinel lymph node (SLN) of early-stage breast cancer patients:

1. Should these patients receive adjuvant treatment?

2. Should these patients undergo completion level I and II axillary lymph node dissection (ALND)?

A recent retrospective publication in the New England Journal of Medicine provides an answer to the first of these questions: de Boer and colleagues compared large cohorts of early-stage breast cancer patients with isolated tumor cells or micrometastases in the SLN who did and did not receive adjuvant treatment. ${ }^{2}$ The authors found adjuvant therapy to be associated with improved disease-free survival. In our investigation, 26 out of 27 patients with SLN micrometastases underwent adjuvant treatment.

The answer to the second question is more challenging. To our knowledge, our prospective investigation is the first in the literature that presents an unselected cohort of earlystage breast cancer patients with SLN micrometastases, in whom a level I and II ALND was systematically omitted. In our study, no local, regional or distant recurrences occurred in any of the 27 patients with SLN micrometastases during a median follow-up of 77 months. Our findings are corroborated by a recent publication by Bilimoria et al. ${ }^{3}$ Based on a large national cancer database, they identified 2,203 patients with microscopic nodal metastases. No significant difference with respect to axillary recurrence and survival was found between patients who underwent completion ALND versus those who did not.
It is well known that the short- and long-term sequelae after ALND are considerable and significantly higher than after SLN procedure alone. ${ }^{4}$ Therefore, it is imperative that breast surgeons carefully consider whether or not an ALND is indicated and if there is any benefit at all to the patient.

In summary, based on the current literature, SLN micrometastases in early-stage breast cancer patients appear to have prognostic value and should impact decisionmaking regarding adjuvant therapy; however, they do not necessarily require further surgical treatment.

Ulrich Guller ${ }^{1}$, Igor Langer ${ }^{2}$, and Markus Zuber ${ }^{3}$

${ }^{1}$ Department of Surgery, Divisions of General Surgery and Surgical Research, University Hospital Basel, Basel,

Switzerland;

${ }^{2}$ Department of Surgery, Bruderholz Hospital, Bruderholz, Switzerland;

${ }^{3}$ Department of Surgery, Kantonsspital Olten, Olten,

Switzerland

e-mail: igor.langer@ksbh.ch

Published Online: 10 December 2009

(C) Society of Surgical Oncology 2009

\section{REFERENCES}

1. Langer I, Guller U, Viehl CT, Moch H, Wight E, Harder F, et al. Axillary lymph node dissection for sentinel lymph node micrometastases may be safely omitted in early-stage breast cancer patients: long-term outcomes of a prospective study. Ann Surg Oncol. Published online: 4 September 2009. doi:10.1245/s10434009-0660-9.

2. de Boer M, van Deurzen CH, van Dijck JA, Borm GF, van Diest PJ, Adang EM, et al. Micrometastases or isolated tumor cells and the outcome of breast cancer. N Engl J Med. 2009;361(7):653-63.

3. Bilimoria KY, Bentrem DJ, Stewart AK, Winchester DP, Ko CY. Comparison of commission on cancer-approved and -nonapproved hospitals in the United States: implications for studies that use the National Cancer Data Base. J Clin Oncol. 2009;27(25):4177-81 (Epub 27 July 2009).

4. Langer I, Guller U, Berclaz G, Koechli OR, Schaer G, Fehr MK, et al. Morbidity of sentinel lymph node biopsy (SLN) alone versus SLN and completion axillary lymph node dissection after breast cancer surgery: a prospective Swiss multicenter study on 659 patients. Ann Surg. 2007;245(3):452-61. 